\title{
Assessment of Potential Improvements to Metro-Bus Transfers in Bangkok, Thailand
}

\author{
Tristan Cherry and Craig Townsend
}

\begin{abstract}
The rail rapid transit (metro) systems in Bangkok, Thailand, lack good intermodal connections. Actions that could improve connections between metros and buses are specified. More than 300 surveys were used to identify passenger perceptions of specific conditions of transfers between subway stations and buses. Passengers expressed high levels of dissatisfaction with specified conditions and the overall transfer experience; this finding suggests that intermodal metro-bus transfers could be greatly improved. The information was used to calibrate importancesatisfaction analysis and ordinal regression models. Model results suggest that the conditions that could have the greatest effect on the overall transfer experience are safety from crime and the distance between subway exits and bus stops.
\end{abstract}

Elevated and underground rail rapid transit (metro) systems, opened in stages since 1999, have added to the capacity and quality of the large public transportation system in Bangkok, Thailand. However, the distribution of benefits has been limited, in part because fares have been set at levels high enough to pay for all operating costs and some capital costs of construction. Furthermore, with no fare-free transfers, passengers must pay for each trip.

Bangkok is a large metropolitan area of more than 10 million inhabitants, and the 50 miles of railway and 53 stations in operation as of 2011 are insufficient to meet mass demand for fast, affordable, and comfortable travel. But beyond this shortcoming, a lack of supportive transport infrastructure has further truncated the spatial distribution of benefits; sidewalks and bus routes, which are crucial to the success of rail rapid transit, are inadequate in many ways. The potentially positive impacts of expanding regional accessibility also have been constrained by a lack of fare integration and physical connectivity between separate transit systems. Many proposals have been made to improve links between premium-quality metro rail infrastructure and the rest of the public transit system as well as to make the metro rail infrastructure accessible to larger segments of the population (1, pp. 6-12;2). Much remains to be done to spread the positive impacts over a larger area and to lower-income segments of Bangkok society.

The overall objective of this paper is to identify specific actions that could improve connections between metros and buses in Bangkok. It proposes measures to improve amenities, increase the accessibility of bus stops, enhance the complementarity and regularity of

Department of Geography, Planning, and Environment, Concordia University, 1455 De Maisonneuve Boulevard West, Montreal, Quebec H3G 1M8, Canada. Corresponding author: C. Townsend, townsend@alcor.concordia.ca.

Transportation Research Record: Journal of the Transportation Research Board, No. 2276, Transportation Research Board of the National Academies, Washington, D.C., 2012, pp. 116-122.

DOI: 10.3141/2276-14 bus routes, and reinforce feelings of safety and security. Methods used by Iseki and Taylor in Los Angeles, California, are adapted to construct a survey for subway passengers regarding subway-bus transfer conditions and then to carry out a two-step analysis (3). First, importance-satisfaction (I/S) analysis is conducted to determine user perceptions of subway-bus transfer conditions; then, ordinal logistic regression analysis is used to identify which specific conditions influence the overall experience of a subway-bus transfer. This paper makes an original contribution through the application of service quality assessment in a developing-world context, where little attention has been paid to coordinating multimodal public transit.

\section{PUBLIC TRANSIT AND INTERMODALISM}

Bangkok suffers from automobile saturation, which greatly degrades the quality of everyday life. As in many cities in the developing world, activity in Bangkok is too dense to accommodate mass automobility, but public transit services and supporting collective goods (e.g., feeder bus networks and sidewalks) are inadequate. Buses run or licensed by the government's Bangkok Mass Transit Authority (BMTA) vary in price and quality but are affordable to most people. However, with most streets lacking space dedicated to buses, people often must board buses under difficult circumstances. Bus speeds are low-around 7.5 miles per hour - and departure times are unpredictable because the road network is frequently saturated. Privately run, competitive paratransit modes are faster and take passengers closer to their destinations for negotiated fees paid to a driver, who often also is the owner of the vehicle. As household incomes have risen, people with the means to own or lease private cars or motorbikes for personal transport have abandoned public transit and paratransit. The additional vehicles then add to external costs such as congestion and air pollution.

In recent years, three rail rapid transit systems have provided some relief from these conditions, offering fast travel; predictable and frequent departures; and spacious, air-conditioned interiors. The elevated Bangkok Transit System (BTS) and the underground Mass Rapid Transit (MRT) subway are operated by private concessionaires. The newest system, opened in 2010, is a government-operated elevated train (Airport Rail Link) to the airport, with commuter stations along the way. On all three systems, the nontransferable fares are set at a level intended to generate profits after the operating costs and some equipment costs have been paid.

Despite proposals and some unsuccessful attempts, government has not taken action to plan an integrated metro network or to coordinate the bus services, surrounding infrastructure, and land uses. The environments surrounding most stations are inhospitable for walking, but paradoxically, long walks are required for metro-bus 
transfers because bus stops were not moved close to metro station exits and street networks are relatively impermeable. Observed egress trips at six BTS and MRT stations in 2006 averaged 866 feet (4). At one of the elevated stations opened in 2010, no bus route or parking facility is located near the station, which also is out of walking distance from surrounding buildings. Because of the lack of decent public sidewalks, the private owner-operator of the elevated BTS system has been constructing grade-separated walkways that link station platforms directly to surrounding buildings. Usually built with the financial support of building owners, such walkways provide a high-quality walking surface free from commonplace sidewalk obstacles (e.g., utility poles, construction debris, street vendors, and motorcycles).

The results of past studies and anecdotal evidence indicate that many passengers who use the metro rail systems transfer to or from another mode of transport, including BMTA buses. However, a significant amount transfer to metered sedan taxis, illegal motorcycle taxis, converted pickup trucks, or minibuses that serve suburban areas and offer point-to-point service for a fee. The prevalence of these low-capacity legal and illegal services appears to be a response to the inadequate provision of bus service and intermodal transfer facilities. Clearly, much could be done to improve metro-bus transfers and discourage further motorization in Bangkok.

\section{QUALITY OF PUBLIC TRANSIT SERVICE}

Overall public transit service quality is determined by several attributes, including the quality of connections between public transit vehicles (5). Transfers between public transit vehicles require linked walking trips and waiting time. Out-of-vehicle time can be quantified and added to the total time (and monetized into the travel costs) of using public transit. However, research suggests that out-of-vehicle travel is perceived by users as longer (and thus more costly) than invehicle travel time $(5-10)$. Transfer time reportedly is perceived as between 1.1 and 4.4 times as long as time spent traveling (11). The extent of the analysis of this disutility is such that out-of-vehicle travel times are applied with rules of thumb (12).

Reducing transfer length and improving transfer conditions could increase overall satisfaction with travel by public transit (3). Highquality pedestrian infrastructure at bus stops and transit terminals could reduce the annoyance and extra time associated with transferring between vehicles. Improved intermodal connections offer the potential of ridership gains without the capital-intensive expansion of infrastructure and services $(13,14)$.

Under the auspices of the Transit Cooperative Research Program (TCRP), several methods of measuring public transit service quality on the basis of user perceptions have been proposed $(11,15)$. Studies that measure the quality of service can be divided into those that determine service attribute coefficients with mathematical modeling procedures and those that describe service quality with statistical descriptions (16). In this paper, both descriptive statistical techniques and mathematical models are used to provide recommendations for service quality improvements in Bangkok.

\section{STUDY METHODOLOGY}

To identify the specific intermodal transfer conditions for assessment, previous research was reviewed. A study in Cosenza, Italy, uses walking distance to bus stop, bus frequency and reliability, and bus stop facilities as attributes related to transfers in a study of the wider attributes of service quality (16). A study in Thessaloniki and Athens, Greece, identifies walking distance, information provision, amenities, safety, and waiting time as factors influencing satisfaction with public transportation (17). A study in Los Angeles assesses transfer facility amenities, information, reliability, station area accessibility, and security from crime as attributes related to transfers as a part of a wider service quality assessment (3). In that study, the characteristics of transfer facilities were found to be less important than sense of personal safety and the frequency and reliability of the transit service.

A survey specifying nine intermodal transfer conditions (phrased as statements) relevant to the Bangkok context was proposed, pretested, and refined. Respondents were asked to rank from 1 to 4 the level of importance and satisfaction with each of the nine conditions at the station exit where they were being interviewed; the four possible responses were 1 (strongly disagree), 2 (disagree somewhat), 3 (agree somewhat), and 4 (strongly agree). A 10th statement ("This is a good place to transfer to a bus") sought to elicit MRT riders' perspectives on the overall transfer experience at the station exit where they were being interviewed. Later in the study, this final statement was used as a dependent variable.

Translated and administered in the Thai language, the statements regarding intermodal transfer conditions (short version in parentheses) follow:

1. There are enough seats where I can sit and wait. (Places to sit)

2. There is shelter to protect me from the sun and rain. (Bus shelter)

3. There are signs around the exits to help me find my way. (Signs)

4. The bus stops are close and easy to find. (Bus stop location)

5. I won't have to wait long to catch a bus. (Wait time)

6. The bus routes from here will take me where I need to go. (Bus routes)

7. The sidewalks here make it easy to walk. (Sidewalk quality)

8. There is a safe and convenient spot to cross the street. (Safe street crossing)

9. I feel safe from crime around this exit. (Safety from crime)

10. This is a good place to transfer to a bus. (Overall)

The survey was administered at five exits at three MRT stations (one at Lumphini, two at Petchaburi, and two at Lad Phrao). These three subway stations were selected because they differ in several ways, including network location and distance to the central business area, activity and building density of the immediate surroundings, and quantity and quality of pedestrian infrastructure. Capturing various metro-bus service characteristics at stations located in distinctly different urban settings was important to generate findings that could be generalized to all stations. At the selected station exits, trained interviewers approached individuals coming out of the station doors and asked them to participate in the survey. The wide sample of passengers included regular and infrequent bus riders.

A two-step analysis was conducted. First, I/S methods were applied to prioritize the metro-bus transfer conditions by treating overall customer satisfaction as a function of the ratio between stated importance and stated satisfaction. In this way, individual scores for satisfaction were weighted according to relative importance. Because all service attributes were not equally important, correcting satisfaction scores according to some measure of importance allowed satisfaction scores to be more reflective of users' needs. 
Iseki and Taylor developed an I/S index based on the methods reported by a similar survey conducted by the Tennessee Department of Transportation (3). I/S scores were calculated by multiplying the number of responses indicating satisfaction by one minus the number of respondents who were satisfied with a specified attribute (indicated by a 3 or 4 on the questionnaire) multiplied by one minus the proportion of respondents who thought the attribute to be very important to overall service.

Next, ordinal logistic regression models were built to determine which service attributes most influenced an MRT passenger's overall satisfaction with the transfer experience. Two series of ordinal regression models were calibrated with the stated satisfaction data. Each question was modeled individually, with each level of satisfaction included as a binary variable. The results indicated which improvements to service would most influence customer satisfaction in a stand-alone format. Next, a multiple ordinal regression model was constructed to determine which variables would most improve customer satisfaction while other significant variables are held constant. In both modeling procedures, the treatment variables were the responses (ranked from 1 to 4 ) of the nine questions related to service attributes, and the dependent variable was the final question that asked users to rank their feelings concerning the importance of and satisfaction with the overall MRT-bus transfer experience at that particular location. Ordinal logistic regression is well suited for analyzing survey data when an ordered difference exists between consecutive categories in the dependent variable but the scale is unknown. Ordinal regression estimates one coefficient for all levels minus one for each of the ranking variables.

\section{STUDY RESULTS}

Data collected in the I/S portion of the survey are listed in Table 1. Columns related to importance contain the average value of importance respondents indicated toward each of the MRT-bus transfer conditions and the variances within the responses; the rates indicate the proportion of respondents who ranked the level of importance attributed to the transfer condition as strongly agree (4). The columns related to satisfaction are the same but contain the rates and statistics for overall stated satisfaction; rate is the proportion of respondents who indicated they were satisfied (3) or very satisfied (4) with a particular service attribute. Variances are shown to illustrate those attributes that respondents rated heterogeneously.

The last two columns in Table 1 list the calculated I/S rate for each service attribute and the overall weighted satisfaction rank of each attribute. Higher I/S values indicate a greater need for improvement. An I/S score would equal 1 when no respondents reported satisfaction with an attribute and all respondents indicated they considered that attribute to be very important. Conversely, an I/S score would equal 0 when all respondents indicated they were satisfied with that attribute and no individuals considered the attribute to be very important. Averages of the mean, variance, and I/S scores within each service factor also are displayed. These values can allow comparisons of how important and satisfied customers are with each factor (3). The results are general findings from a diverse set of metro station exits. For specific planning purposes, the findings would have to be disaggregated to the individual station level.

Respondents indicated that safety from crime was the most important $(65 \%)$ aspect of transfer quality (Table 1). At three of the five exits surveyed, bus stop access requires a walk longer than 3 minutes, on average. At stations that lack integrated bus platforms or nearby connections, patrons undoubtedly feel unprotected, particularly if they must transfer after dark. Perhaps unsurprisingly, respondents considered the location of bus stops the next most important $(59 \%)$ attribute to transfer quality. The two attributes related to performance and reliability also were important to overall service, whereas wait times and available routes connecting to the stations tied as the third most important (52\%) attribute. The most important conditions were related to safety and security around the stations and to the reliability and performance of bus service; physical amenities at the bus stops were less important.

Overall, the average rates of satisfaction with intermodal transfer conditions were low compared with the $85 \%$ of respondents in Los Angeles who indicated that they felt at least somewhat safe from crime during the day (3). In the present study, only $62 \%$ of customers were at least somewhat satisfied with being safe from crime

TABLE 1 I/S Analysis Data for All Respondents

\begin{tabular}{|c|c|c|c|c|c|c|c|c|}
\hline Service Attribute & Mean & Variance & Rate $(\%)$ & Mean & Variance & Rate $(\%)$ & Rate $(\%)$ & Rank \\
\hline Places to sit & 0.782 & 0.053 & 39.0 & 0.635 & 0.050 & 58.0 & 16.0 & 8 \\
\hline Bus shelter & 0.806 & 0.046 & 43.0 & 0.633 & 0.055 & 51.0 & 21.0 & 5 \\
\hline Signs & 0.785 & 0.051 & 40.0 & 0.679 & 0.052 & 65.0 & 14.0 & 9 \\
\hline Wait time & 0.830 & 0.048 & 52.0 & 0.614 & 0.060 & 47.0 & 27.5 & 1 \\
\hline Bus routes & 0.834 & 0.047 & 52.0 & 0.661 & 0.059 & 58.0 & 21.8 & 4 \\
\hline Safe street crossing & 0.816 & 0.048 & 48.0 & 0.663 & 0.053 & 57.0 & 20.6 & 6 \\
\hline
\end{tabular}

NoTE: $-=$ not applicable.

${ }^{a}$ Average is the mean value for each of columns above and cannot receive a rank.

${ }^{b}$ This row is a dependent variable, not a service variable, and is therefore not ranked. 
during transfers; the average rating for safety from crime was $68 \%$, with a variance of about $5 \%$, similar to other attributes but very high considering the grave implications it may have on bus ridership levels. Metro passengers were very satisfied with the presence of signage at metro stops (65\%) but found them unimportant when making transfers $(40 \%)$. Customers were equally satisfied with three attributes from three of the service factors; $57 \%$ of respondents were at least somewhat satisfied with the location of bus stop locations (reflecting the opinions of stop locations at Lad Phrao Station, where several busy bus stops are located a short distance from one of the exits), their safety and ability to cross the street, and the overall quality of the sidewalks. Customers were relatively unsatisfied with the availability of shelters at stops and wait times for buses.

According to I/S calculations, wait times at bus stops (27) require the most immediate attention to ensure overall service quality, followed by safety from crime (26). Bus stop locations (25) also ranked as a service quality aspect that needs attention. Routes (22) and shelters at stops (21) and street crossings (20) were in the middle, whereas sidewalks (18), places to sit (16), and signage at stations (14) should be of the least concern for immediate improvement. Although sidewalks were rated as relatively unimportant, the variance was very low, indicating that users ranked this attribute homogeneously as somewhat important to overall transfer conditions.

Figure 1 is a quadrant analysis chart illustrating the relative satisfaction and importance that respondents place on each service quality attribute. The $x$-axis shows the proportion of respondents who indicated that the service attribute was very important, and the $y$-axis shows the proportion of respondents who reported that they were at least somewhat satisfied with the current state of service. Average satisfaction and importance rates are indicated by the lines.

The top left quadrant contains service attributes that users are more satisfied with but consider to be less important to their needs; transfer conditions that fall into this quadrant for planning purposes can be considered adequately provisioned. The top right quadrant contains attributes that are above average in importance and satisfaction; these responses represent areas of service that are being well provided but need constant consideration because customers perceive these attributes as relatively important. All four service attributes in this quadrant—crime, bus routes, crosswalks, and bus stop location-are very close to the average of satisfaction and measurably higher in stated importance.

Across all service attributes, average satisfaction in this survey is $49 \%$, which is low by any service industry standards. The bottom left quadrant contains attributes that are below average in both importance and satisfaction. Curiously, shelter was the only attribute to fall in this category. For planning purposes, attributes found here should be considered low priorities relative to other services. Attributes in the bottom right quadrant are in need of immediate attention and should be considered top priorities for improvement. Even though it is not considered to be as important to overall service as bus stop locations, the attribute of wait times for buses is well below the average rate of satisfaction and is expressed by user weighted satisfaction scores as the service attribute in greatest need of improvement.

\section{Ordinal Logistic Regression}

Results for the series of individually modeled variables are listed in Table 2. For each model, all 310 valid responses were tested. All reported variables are significant at the $95 \%$ confidence level, and each model's fit was verified by Pearson goodness-of-fit statistics $\left(\chi^{2}>0.05\right)$, which are not reported here. The levels indicate the individual dummy categories of the independent variables that were observed to influence significantly the log odds of choosing a particular level of overall satisfaction.

Because ordinal regression tests for the occurrence of the cumulative odds of an event and all events ordered before it, each model

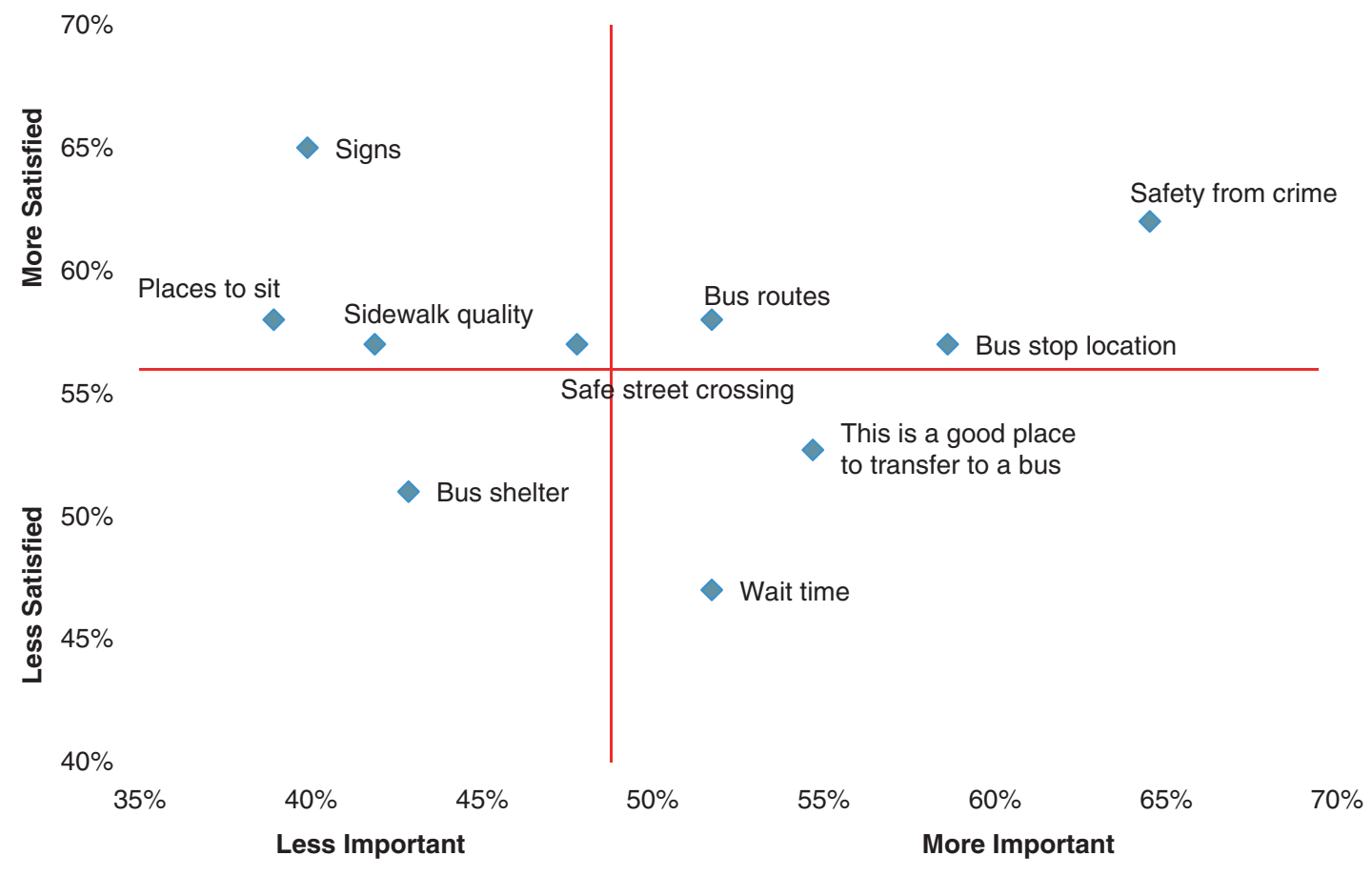

FIGURE 1 I/S quadrant analysis chart (importance and satisfaction rates from Table 1). 
TABLE 2 Ordinal Regression Models $(N=310$ valid responses $)$

\begin{tabular}{lcccc}
\hline Variable & $\begin{array}{c}\text { Satisfaction } \\
\text { Level }\end{array}$ & Pseudo- $R^{2}$ & Coefficient & $\begin{array}{c}\text { Parallelism } \\
(p \text {-value })\end{array}$ \\
\hline Places to sit & 4 & .02 & 0.466 & .234 \\
Bus shelter & 4 & .03 & 0.846 & .567 \\
Signs & 4 & .04 & 0.911 & .331 \\
Bus stop & 3 & .18 & 0.940 & .386 \\
$\quad$ location & 4 & .18 & 2.210 & .386 \\
Wait time & 4 & .15 & 2.108 & .216 \\
Bus routes & 2 & .15 & -0.315 & .082 \\
Bus routes & 4 & .15 & 1.026 & .082 \\
Sidewalk & 2 & .04 & -0.658 & .318 \\
$\quad$ quality & 3 & .04 & 0.605 & .318 \\
Safe street & 4 & .04 & 0.911 & .318 \\
$\quad$ crossing & 4 & .05 & 0.642 & .930 \\
Safety from & & & & .123 \\
$\quad$ crime & 4 & .11 & 0.923 & \\
\hline
\end{tabular}

tests for the probability of only three levels; testing for all categories would be redundant. Each model is reported with a pseudo- $R^{2}$ value that cannot be interpreted as an $R^{2}$ value in an ordinary least squares regression model. Logistic regression is achieved though maximum likelihood estimates and does not minimize variance. Instead, a pseudo- $R^{2}$ value is the ratio of the likelihoods of the saturated model (with predictors) and the constrained model without any predictors (18). A higher $R^{2}$ value indicates a better model fit.

Even though comparisons should be made with caution, pseudo$R^{2}$ values are used here to gauge the relative performance of each attribute in influencing the odds of selecting a level of satisfaction or higher (3). The coefficients are the ordered logit coefficients for the predictor variables. For every change in a given predictor variable [e.g., from satisfied (3) to very satisfied (4)], the ordered logodds of the level of the response variable is expected to change by the respective coefficient. An assumption of ordinal logistic regression is that all categories of the independent variable have the same coefficient with different intercepts, which is why the test is often called the proportional odds model (18). The parallelism $p$-value reflects the $p$-value used to verify this assumption. In all reported models, one can fail to reject the null hypothesis of parallelism, indicating the assumption that each coefficient that describes each level of overall satisfaction has approximately the same slope in any single model.

The results of the simple ordered logistical regression determined the overall magnitude each intermodal transfer condition has on influencing customer perceptions without controlling for the presence of other attributes. Examination of the coefficients and pseudo$R^{2}$ indicates that the bus stop location is the most important attribute to respondents, testing significantly at two levels of satisfaction (i.e., satisfied and very satisfied). The .18 pseudo- $R^{2}$ explains that the model that included bus stop location to predict overall satisfaction with transfers showed the greatest improvement over a model that contained no predictors. When an individual selects very satisfied (4) with bus stop location, the ordered log odds of that individual moving to a higher category of overall satisfaction is 2.1 .

After bus stop location, the predictor that improved the most on constrained models was available routes at the station exits, which is significant at two levels (somewhat unsatisfied and very satisfied) with a pseudo- $R^{2}$ of .15 . The negative coefficient for individuals who selected somewhat unsatisfied (2) with the routes of connecting buses indicates that the log odds that those people will select a higher category of satisfaction decreases by -0.315 .

The third-best individual predictor of overall satisfaction was wait time at very satisfied (4), which has a pseudo- $R^{2}$ of .15 , followed by safety from crime (pseudo $R^{2}=.11$ ). In comparison, even though individual variables related to amenities, available signage, and cross walks were significant [very satisfied (4)] in influencing the odds of choosing a level of overall satisfaction, these attributes were considerably less important than the others. One exception is the sidewalk quality attribute, which tested significantly across all levels of satisfaction. This finding suggests that sidewalk quality exerts influence on the overall transfer experience at all levels of satisfaction, a unique property among all attributes tested.

\section{Multiple Ordinal Regression}

The final stage of analysis determined which intermodal transfer conditions can be used to increase satisfaction while other relevant attributes are held constant. A final list of service attributes that most influence overall satisfaction with MRT-bus transfers while controlling for the other service measures is presented in Table 3. The final model that tested all 310 observations used a logit link function and is parsimonious in that it contains only service attributes at levels that statistically influence overall satisfaction in a significant way. Overall, the model adequacy is tested by comparing the change in the $-2 \log$ likelihoods (L.L.) when the treatment variables are added to a model that contains only an intercept. The saturated model has a lower final value, which is significant improvement at the 0.95 confidence level. The assumption of parallel lines also is retained ( $p$-value = .06). The pseudo- $R^{2}$ value of .248 is an improvement on candidate models, which used the complementary log (clog-log) link function where some of the assumptions of parallelism are relaxed (19).

Discarded candidate models also tested for the significance of the respondent's sex, income, and reported egress trip. Research results indicate that none of these contextual variables influenced a respondent's overall satisfaction with the quality of bus connections in a statistically meaningful way. Segmenting analysis according to sex or next reported mode also yielded insignificant results. While disappointing, this lack of significance does not

TABLE 3 Multivariate Ordinal Regression Model $C N=310$ valid responses]

\begin{tabular}{lcccc}
\hline Variable & Level & Coefficient & $\operatorname{expB}$ & $p$-Value \\
\hline $\begin{array}{l}\text { Bus stop } \\
\text { accessibility }\end{array}$ & 4 & 1.040 & 2.829217 & .000 \\
$\begin{array}{l}\text { Wait time } \\
\begin{array}{l}\text { Bus route } \\
\quad \text { connectivity }\end{array}\end{array}$ & 4 & 0.856 & 2.353727 & .001 \\
$\begin{array}{l}\text { Safety from } \\
\text { crime }\end{array}$ & 4 & 1.012 & 2.751098 & .019 \\
\hline
\end{tabular}

NotE: $\operatorname{expB}=$ exponentiated coefficient; $-2 \log$ likelihood (L.L.) of constrained model (i.e., model that contains no effects of any predictor values) $=207.58$; saturated -2 L.L. of model that has all predictor variables added $=128.34 ;$ likelihood ratio (difference between constrained and saturated models $)=79.24 ;$ parallelism $p$-value $=.059 ;$ pseudo- $R^{2}=.25$. 
diminish the general findings of the research and the applicability of service improvements at Bangkok metro exits.

The final multivariate model determined four of the nine service variables significant, all at the highest level of satisfaction. These four attributes that together significantly influence overall satisfaction with transfers are listed in Table 3. Because the final model used the logit-link function and tests for users' overall satisfaction in all categories, coefficients in this case can be reliably compared. A larger coefficient indicates that the attribute has a greater overall magnitude on influencing the odds an individual will choose a higher category of satisfaction. Controlling for other significant attributes, bus stop location relative to station exit and available bus routes were the most important service characteristics influencing overall satisfaction with transfers. In other words, MRT customers who are happy with bus stops that are close and convenient to exits with routes available that travel where they need to go are significantly more likely to evaluate their transfer experiences positively. High satisfaction scores for wait time and perceived safety from crime were significant in reducing the odds that individuals were unsatisfied with transfers. All other attributes considered in the multivariate model do not significantly increase or decrease the odds of being satisfied with making transfers.

Just as in binary logistic regression, coefficients in ordinal regression can be exponentiated and reported as proportional odds ratios. In this way, all exponentiated coefficients $(\operatorname{expB})$ are interpreted as the odds that the outcome will change given the predictor variable. Table 3 reports the odds ratio of each coefficient. All independent variables are binary $(1,0)$ of whether or not an individual selected 4 (very satisfied). Individuals who were very satisfied with bus stop locations were 2.8 times more likely to be in a higher category of satisfaction than individuals who were not very satisfied with the stop locations. Bus routes and wait time had similarly positive results on transfer experience, with safety from crime being a less but still significant determinant factor related to transfer quality.

\section{RECOMMENDATIONS}

This research identified a set of intermodal transfer conditions that users of Bangkok MRT stations feel are most in need of improvement and which of those attributes increase the odds of user satisfaction with transfers. Ideally, service attributes where the findings of the I/S analysis and ordinal logistic regression models closely converge should be prioritized for improvement. A concise set of recommendations to improve the transfer environment at metro stations follow.

\section{Wait Times}

The BMTA does not publish bus headways or post schedules at stops; this absence is a clear disservice to customers. Not only do individuals consider reduced wait times the best way that transfers could be improved, but ordinal regression model results also indicate that individuals who feel that wait times are acceptable are 2.3 times more likely to be pleased with transfers. Posted schedules and timed vehicle headways can reduce the anxiety involved with waiting and allow customers to schedule trips in advance. The BMTA should consider decreasing headway times between buses (particularly during peak periods) and scheduling bus arrivals. More regular bus arrivals would likely involve providing bus priority lanes because much of the road network is saturated.

\section{Bus Stop Locations}

Customers are happier with transfers at stations where bus stops are conveniently located and simple to access. Repositioning bus stops so passengers may safely board buses at a reasonable distance from the station exits would diminish some unnecessary penalties associated with bus use. At Petchaburi and Lumphini Stations, moving bus stops closer to the station exits would require a significant reconfiguration of existing roadways, thus necessitating trade-offs between vehicle capacity and bus accessibility.

\section{Bus Routes}

Users generally are unsatisfied with available routes and more satisfied with transfers that have bus routes aligned with their destinations. The BMTA should restructure routes to serve subway passengers more effectively and eliminate redundancies in routes that track the metro's path. Since the Bangkok metro opened, routes have not been reorganized to feed into and out of the heavy rail services (2). Better coordination between services is necessary for improvement.

\section{Safety from Crime}

Personal safety from crime is a significant attribute that influences satisfaction and is perceived as needing improvement. Liggett et al. find that the built environment and bus stop characteristics are significantly correlated with the incidence of crime against transit customers (20). The presence of bus shelters, pedestrian activity volume, and visibility to surrounding buildings all significantly influence crime incidence, and much could be done at Bangkok metro stations to improve these characteristics. Expanding and improving sidewalk quality, reducing curb heights, and removing obstructions (e.g., telephone booths, poorly positioned utility poles, and construction debris) would improve the quality of the pedestrian environment. Eliminating concrete barriers that partition sidewalks from adjacent buildings would not only improve sidewalk aesthetics but also increase the eyes-on-the-street effect that has been shown to decrease crime incidence. Treating station areas as public spaces could increase pedestrian volume, which could create a safer waiting environment. Adding pedestrian-level lighting could increase the sense of personal security at and around stations at night.

\section{CONCLUSIONS}

An important finding of this research is that the quality of connections between buses and heavy rail matters to riders in Bangkok. Not only do significant portions of metro riders regularly use buses, but $48 \%$ are also unsatisfied with the present interconnectivity and more than $80 \%$ believe transfers to be an important aspect at station exits. Thus far, little has been done to integrate bus facilities with metros, and coordination between transit agencies is minimal. Results of this research indicate that subway passengers recognize the problems with intermodal transfer conditions and are aware of what could be done to improve them. 
I/S analysis and ordinal logistic regression can be used to determine which basic improvements to services would best support the improvement of metro-bus transit service quality according to customer perceptions. At five exits around three metro stations in Bangkok, 310 respondents indicated their levels of satisfaction with the present state of nine transfer conditions, then how important each condition was when making a transfer to a bus. The importance and satisfaction data were used to conduct an I/S analysis, whereas the satisfaction data were used to calibrate ordinal regression models. Results clearly indicate that metro customers consider the bus system to be important, and the present quality of intermodal transfer conditions is deficient. Better coordination between the subway and BMTA buses (particularly on improving accessibility to stops) and environments more conducive to public safety may attract new riders onto buses.

The study has some limitations. One is that only passengers transferring from subway to buses were surveyed, and these public transit users might have had perceptions different from those of wealthy automobile drivers or of poor bus users who are unlikely to use the subway. The future success of public transit in Bangkok will involve expanding service coverage and quality to serve currently underserved groups. However, a fundamental problem is that the metro systems, buses, and even the street and sidewalk space are operated by separate organizations that are controlled by different government ministries. What likely will be needed to bring changes to the system (including fare-free transfers, which could bring the metro within the reach of low-income households) is a high level of government commitment to coordinating the activities of different ministries in ways that promote social and economic development.

\section{ACKNOWLEDGMENTS}

The authors thank Saksith Chalermpong and the Transportation Research Laboratory in the Department of Civil Engineering, Chulalongkorn University, Bangkok, Thailand. The translation services of Pajaree $\mathrm{Na}$ Thalang are greatly appreciated. Financial assistance was provided by the Government of the Province of Quebec, Canada, through a Fonds Québécois de la Recherche sur la Société et la Culture (FQRSC): Etablissement de Nouveaux Professeurs-Chercheurs grant to study the spatial impacts of mass rapid transit in Bangkok.

\section{REFERENCES}

1. Asian Engineering Consultants Corp., Ltd.; Pacific Consultants International; TESCO Ltd.; and Transconsult Co., Ltd. Existing Urban and Regional Transportation Systems and Related Issues. The Intermodal Service Integration for the Improvement of Mobility, Accessibility, Sustainability and Livelihood for the Bangkok Metropolitan Area and the Surrounding Regions. Office of the Commission of Land Management and Traffic, Bangkok, Thailand, 2005.

2. Strategic Urban Transport Policy Directions for Bangkok. World Bank, Washington, D.C., 2007.
3. Iseki, H., and B. Taylor. Style Versus Service? An Analysis of User Perceptions of Transit Stops and Stations. Journal of Public Transportation, Vol. 13, No. 3, 2010, pp. 39-63.

4. Townsend, C., and J. Zacharias. Built Environment and Pedestrian Behaviour at Rail Rapid Transit Stations in Bangkok, Thailand. Transportation, Vol. 37, No. 2, 2010, pp. 317-330.

5. Guo, Z., and N. H. M. Wilson. Modeling the Effects of Transit System Transfers on Travel Behavior: Case of Commuter Rail and Subway in Downtown Boston, Massachusetts. In Transportation Research Record: Journal of the Transportation Research Board, No. 2006, Transportation Research Board of the National Academies, Washington, D.C., 2007, pp. 11-20.

6. Guo, Z., and N. H. M. Wilson. Assessment of the Transfer Penalty for Transit Trips: Geographic Information System-Based Disaggregate Modeling Approach. In Transportation Research Record: Journal of the Transportation Research Board, No. 1872, Transportation Research Board of the National Academies, Washington, D.C., 2004, pp. 10-18.

7. Horowitz, A. J. The Subjective Value of the Time Spent in Travel. Transportation Research, Vol. 12, No. 6, 1978, pp. 385-393.

8. Horowitz, A. J., and N. A. Thompson. Generic Objectives for Evaluation of Intermodal Passenger Transfer Facilities. In Transportation Research Record 1503, TRB, National Research Council, Washington, D.C., 1995, pp. 104-110.

9. Liu, R., R. M. Pendyala, and S. Polzin. Assessment of Intermodal Transfer Penalties Using Stated Preference Data. In Transportation Research Record 1607, TRB, National Research Council, Washington, D.C., 1997, pp. 74-80.

10. Wardman, M. Public Transport Values of Time. Transport Policy, Vol. 11, 2004, pp. 363-377.

11. Kittelson \& Associates, Inc.; KFH Group, Inc.; Parsons Brinckerhoff Quade \& Douglas, Inc.; and K. Hunter-Zaworski. TCRP Report 100: Transit Capacity and Quality of Service Manual, 2nd ed. Transportation Research Board of the National Academies, Washington, D.C., 2004.

12. TCRP Report 46: Amenities for Transit Handbook. TRB, National Research Council, Washington, D.C., 1997.

13. Akin, D. Model for Estimating Increased Ridership Caused by Integration of Two Urban Transit Modes: Case Study of Metro and Bus-Minibus Transit Systems, Istanbul, Turkey. In Transportation Research Record: Journal of the Transportation Research Board, No. 1986, Transportation Research Board of the National Academies, Washington, D.C., 2006, pp. 162-171.

14. Currie, G., and C. Loader. Bus Network Planning for Transfers and the Network Effect in Melbourne, Australia. In Transportation Research Record: Journal of the Transportation Research Board, No. 2145, Transportation Research Board of the National Academies, Washington, D.C., 2010, pp. 8-17.

15. TCRP Report 47: A Handbook for Measuring Customer Satisfaction and Service Quality. TRB, National Research Council, Washington, D.C., 1999.

16. Eboli, L., and G. Mazzulla. A Stated Preference Experiment for Measuring Service Quality in Public Transport. Transportation Planning and Technology, Vol. 31, No. 5, 2008, pp. 509-523.

17. Tyrinopoulos, Y., and C. Antoniou. Public Transit User Satisfaction: Variability and Policy Implications. Transport Policy, Vol. 15, No. 4 pp. 260-272.

18. O'Connell, A. Logistic Regression Models for Ordinal Response Variables. Sage Publications, Thousand Oaks, Calif., 2006.

19. Bender, R., and A. Benner. Calculating Ordinal Regression Models in SAS and S-Plus. Biometrical Journal, Vol. 42, No. 6, 2002, pp. 677-699.

20. Liggett, R., A. Loukaitou-Sideris, and H. Iseki. Bus Stop-Environment Connection: Do Characteristics of the Built Environment Correlate with Bus Stop Crime? In Transportation Research Record: Journal of the Transportation Research Board, No. 1760, TRB, National Research Council, Washington, D.C., 2001, pp. 20-27.

The Intermodal Transfer Facilities Committee peer-reviewed this paper. 